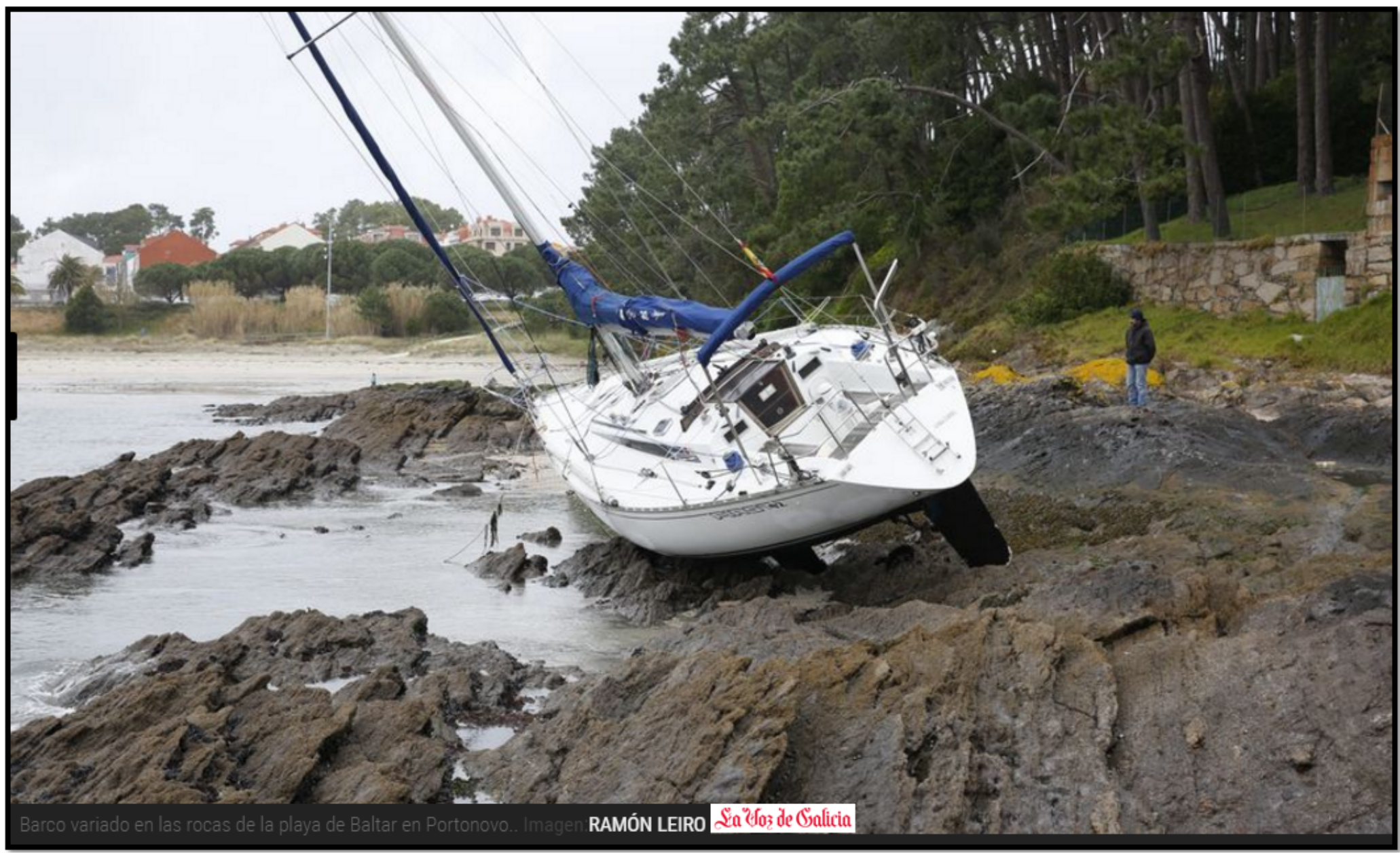

\title{
Temporal marítimo en Galicia (Feb 2017)
}

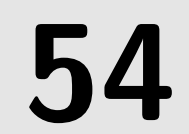

DOI: $10.31978 / 014-18-009-X .54$

FRANCISCO JAVIER DÍAZ BÁRCENA

Área de Predicción Operativa (APRO), Agencia Estatal de Meteorología (AEMET)

José HIERRo CARNICERO

Delegación territorial (DT) en Galicia, AEMET

Asubían os ventos, brúan as raucas olas, ráchanse as brancas velas, fungan as tesas cordas.

Quexumes dos pinos e outros poemas - EDUARDO PONDAL

Se presenta a continuación el proceso de predicción del estado de la mar en las aguas costeras de Galicia con ocasión de un temporal atlántico ocurrido en los primeros días de febrero de 2017. Este proceso comienza de forma temprana en el medio plazo estudiando, con un enfoque probabilista, los diferentes escenarios posibles que podrían dar lugar a situaciones de aviso de fenómenos adversos, tal y como los contempla el plan Meteoalerta (cap. 41 en la página 627) vigente en AEMET. Ya en el corto plazo, entre 48 y 72 horas antes de la ocurrencia de los fenómenos previstos, y con un enfoque crecientemente determinista, se plantea la decisión de emitir avisos, en este caso bajo la responsabilidad del Grupo de Predicción y Vigilancia de A Coruña. Finalmente se contrasta brevemente la predicción realizada con algunos de los datos registrados.

Palabras clave: sistemas de predicción por conjuntos aplicados a la predicción de corto y medio plazo, predicción probabilista, temporal marítimo den Galicia febrero 2017. 


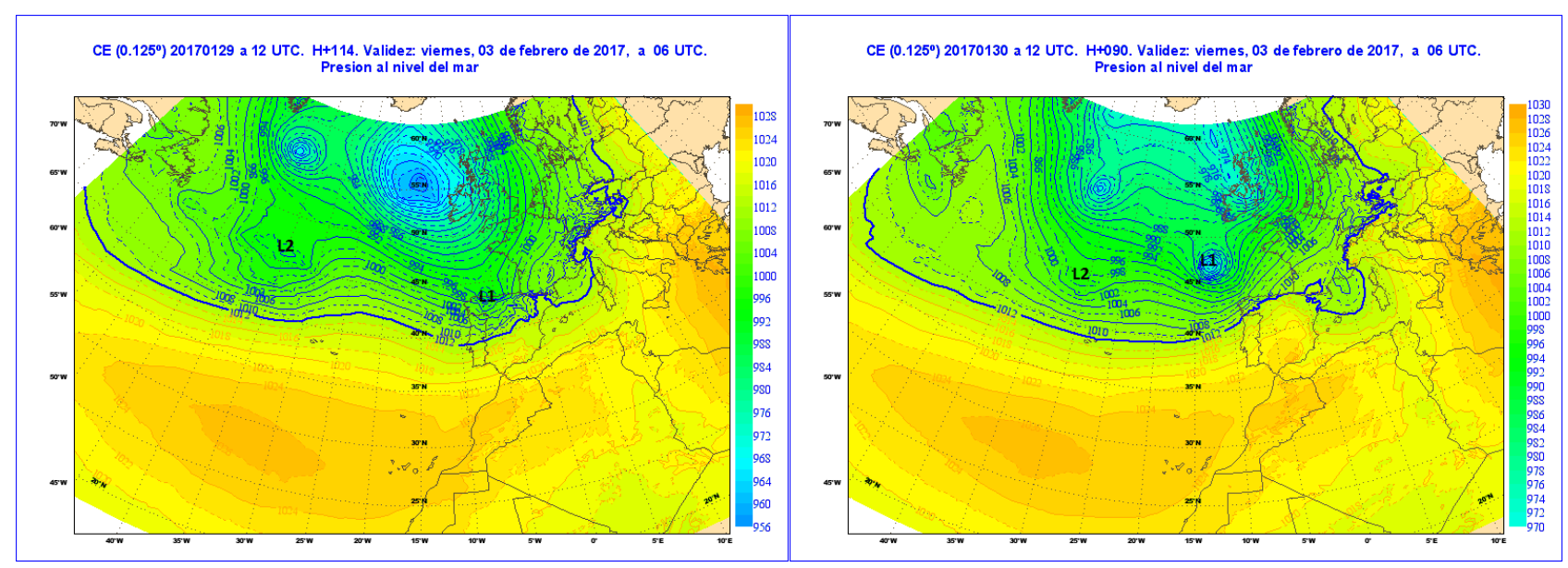

Figura 54.1: Predicción de la presión al nivel del mar para el día 3 a las 06 UTC correspondientes a las pasadas del 29 y el 30 de enero de 12 UTC. Agencia Estatal de Meteorología (AEMET) 2017.

\subsection{Descripción de la situación}

Desde el día 1 hasta el 5 de febrero de 2017, bajo una fuerte circulación zonal en altura con máximos de viento sobre la latitud $45 \mathrm{~N}$ aproximadamente, se fueron produciendo sucesivas ciclogénesis en el Atlántico central que se profundizaban y desplazaban rápidamente al acercarse al noroeste de la península ibérica, para después recorrer el golfo de Vizcaya con rumbo NE hacia el norte de Francia.

Estas ciclogénesis, asociadas a profundización de vaguadas en altura a la salida de fuerte circulación del oeste sobre el Atlántico, no llegaban a cumplir el requisito de explosivas ( $24 \mathrm{hPa}$ en 24 horas) aunque sí cuando se limitaba el criterio a la profundización en 12 horas.

Esta situación produjo episodios de temporal en las costas de Galicia y en menor medida en las del Cantábrico. Nos fijaremos en particular en las dos bajas que pasaron en las madrugadas del 3 y el 4 de febrero cerca del norte de Galicia, que denominaremos L1 y L2 (ver Figura 54.1), y en las dificultades de su predicción.

Aunque las rachas de viento durante este episodio en muchas zonas de la Península alcanzaron valores muy fuertes y las precipitaciones fueron importantes en algunas zonas, prestaremos atención en este estudio fundamentalmente al estado de la mar y las dificultades en la toma de decisión para la emisión de avisos de nivel rojo en las zonas costeras.

Los avisos de fenómenos meteorológicos adversos se describen con detalle en el capítulo dedicado al plan Meteoalerta (cap. 41 en la página 627) vigente en AEMET.

\subsection{Problemática de la predicción}

El aviso rojo en las zonas costeras de Galicia y el Cantábrico se debe emitir por AEMET cuando se prevea alguna de las dos siguientes condiciones: altura significativa de olas de mar compuesta o combinada superior a 8 metros y/o viento medio superior a fuerza 10. En lo sucesivo toda referencia que se haga a altura de ola, prevista u observada, se referirá a la altura significativa que se define como el valor medio del tercio de las olas más altas en el espectro del oleaje. Por otro lado, tradicionalmente se distinguen dos tipos de oleaje que contribuyen al oleaje de mar compuesta o combinada que es el objeto de los avisos: olas por mar de viento y olas por mar de fondo. Las primeras se dan en una determinada zona debidas al viento que en ese momento sopla en esa zona. El oleaje de mar de fondo sin embargo lo ha producido viento que ha soplado durante cierto tiempo sobre una extensión de mar (fetch) propagándose posteriormente hasta la zona objeto de la predicción. En la situación que tratamos, ambas contribuciones son importantes. Sin embargo, tienen una diferencia a efectos de la predicción: su diferente predecibilidad, menor para la mar de viento. Véanse como ejemplo en la Figura 54.2 en la página siguiente los mapas de probabilidad (sección 27.6.1 en la página 416) del SPC del ECMWF (ECENS, sec. 19.3 en la página 293) [1] del 29 de enero previstos para los días jueves 2, viernes 3 y sábado 4 de febrero.

Las dos bajas que tratamos producen vientos muy fuertes y la consiguiente mar de viento, pero sus efectos concretos sobre el litoral gallego y cantábrico van a depender de sus características particulares: trayectoria, cronología de su evolución, profundidad y gradiente de presión producido. 


MAPAS DE PROBABILIDAD // Pasada: 29 En. 2017 a 00 UTC
Altura de olas mar de fondo

$\mathrm{H}+108$ (Jueves) $\mathrm{H}+132$ (Viernes) $\mathrm{H}+156$ (Sabado)

Altura olas mar de fondo superior a $2.5 \mathrm{~m}(10,40,70,90)$
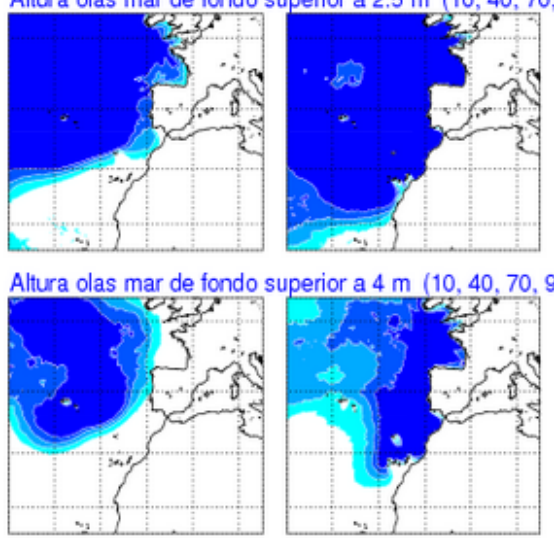

Altura olas mar de fondo superior a $6 \mathrm{~m}(5,10,40,70)$

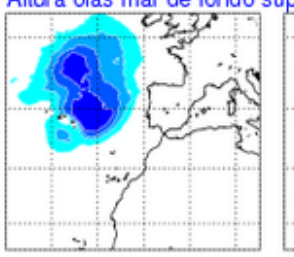

Altura olas mar de fondo superior a $9 \mathrm{~m}(5,10,40,70)$

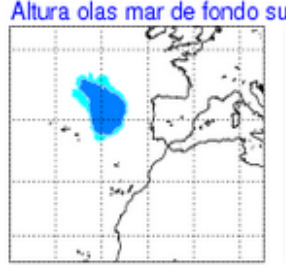

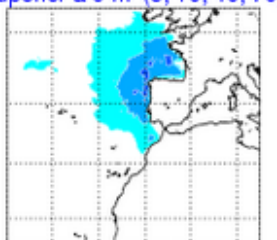
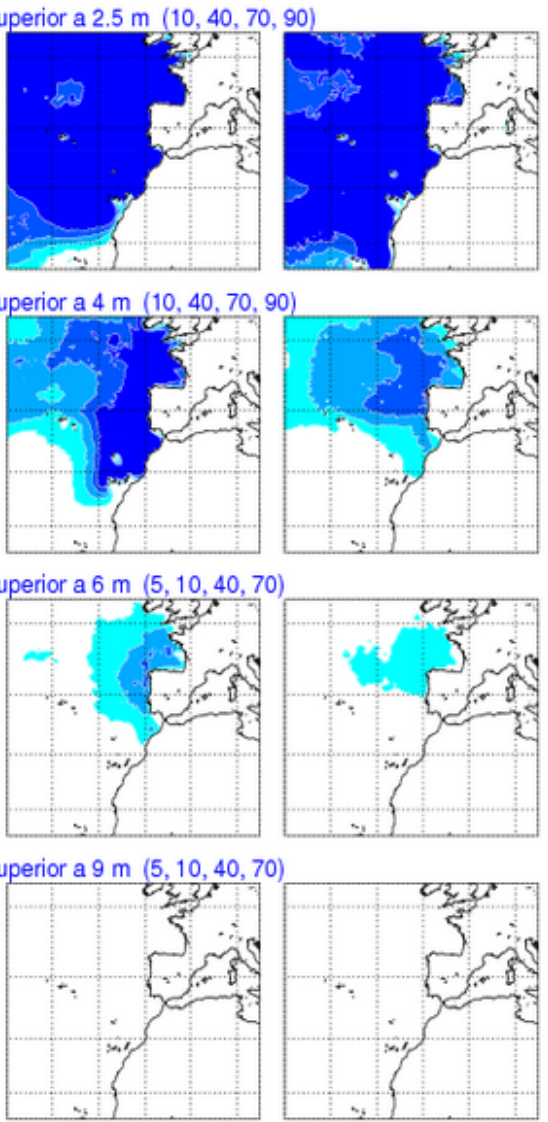

MAPAS DE PROBABILIDAD // Pasada: 29 En. 2017 a 00 UTC Altura de olas mar de viento

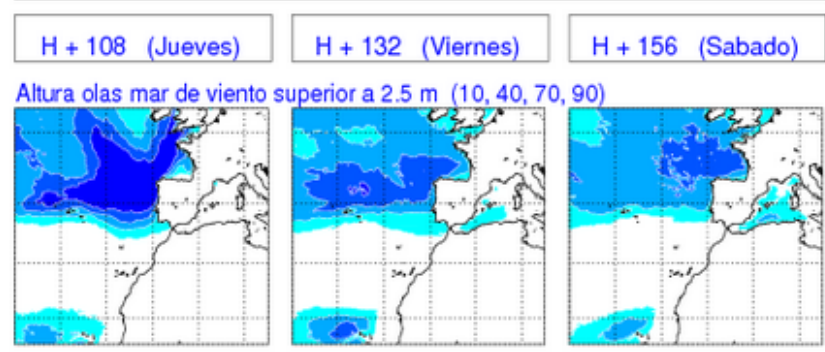

Altura olas mar de viento superior a $4 \mathrm{~m}(10,40,70,90)$

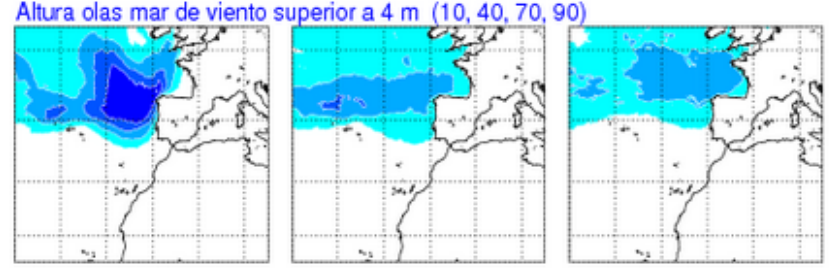

Altura olas mar de viento superior a $6 \mathrm{~m}(5,10,40,70)$

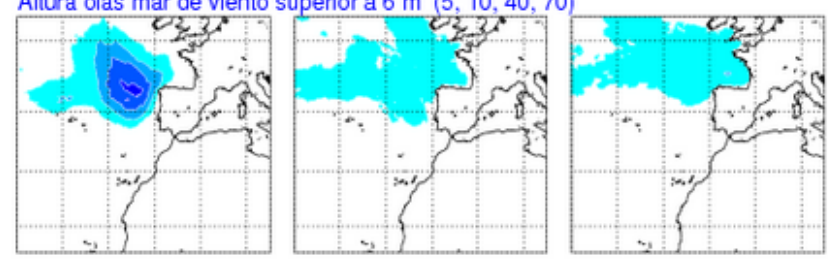

Altura olas mar de viento superior a $9 \mathrm{~m}(5,10,40,70)$

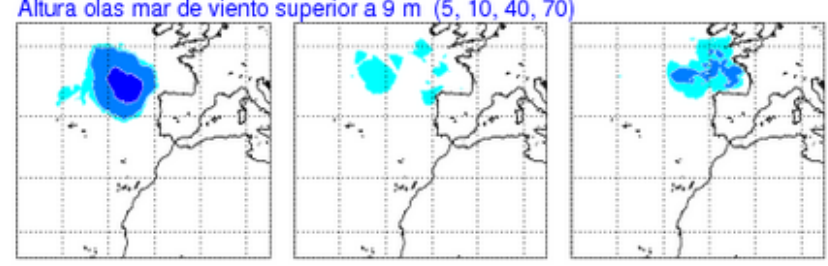

Figura 54.2: Mapas de probabilidad previstos para la altura de olas de mar de fondo y de viento. Para los umbrales 2.5 y 4 m los intervalos de probabilidad son blanco $=0-10 \%$, celeste $=10-40 \%$, azull $=40-70 \%$, azul2 $=70-90 \%$, azul3=90-100\%; para los umbrales de 6 y $9 \mathrm{~m}$ son blanco $=0-5 \%$, celeste $=5-10 \%$, azull $=10-40 \%$, azul2 $=40-70 \%$, azul3=70-100\%). Comparativamente, los mapas correspondientes al mar de viento muestran distribuciones de probabilidad de superación de umbrales más dispersas geográficamente. AEMET 2017.

Pequeñas diferencias en su evolución sinóptica darán lugar a diferentes efectos sensibles (altura de ola y fuerza del viento) en diferentes zonas, lo que cambiará la predicción que se emita y el correspondiente nivel de aviso. Las dudas que acompañan a una situación como la estudiada a la hora de decidir la emisión de avisos de nivel naranja o rojo provendrán en buena medida de la incertidumbre que acompañe a la predicción de estas bajas y del mar de viento que producirán.

\subsection{Inconsistencia de las pasa- das sucesivas del modelo ECMWF de alta resolución ECHRES}

Aunque en este episodio el modelo de alta resolución tuvo un buen comportamiento incluso en el medio plazo, las pasadas sucesivas discrepaban lo suficiente para sugerir predicciones marítimas en Galicia bastante diferentes. Véase como ejemplo la predicción de la presión en superficie (Figura 54.1 en la página anterior) con la posición de las bajas estudiadas L1 y L2 para el día 3 a las 06 UTC de las pasadas del modelo de los días 29 y 30 de enero ambas de las 12 UTC; la del día 30 de enero hace evolucionar L1 mucho más al norte que la del día 29 e incluso que la evolución real (véase la imagen de satélite en la Figura 54.14 en la página 824).

Se hace pues imprescindible en el medio plazo, para empezar, utilizar los recursos de la predicción probabilista para abordar esta situación. La primera herramienta de alerta ante una situación adversa que valora la extrañeza del fenómeno es el Extreme Forecast Index, EFI (sección 27.7.2 en la página 420) que ya el 
día 29 ofrecía un valor llamativo para la altura de mar de los días 2 y 3 de febrero (Fig. 54.3).
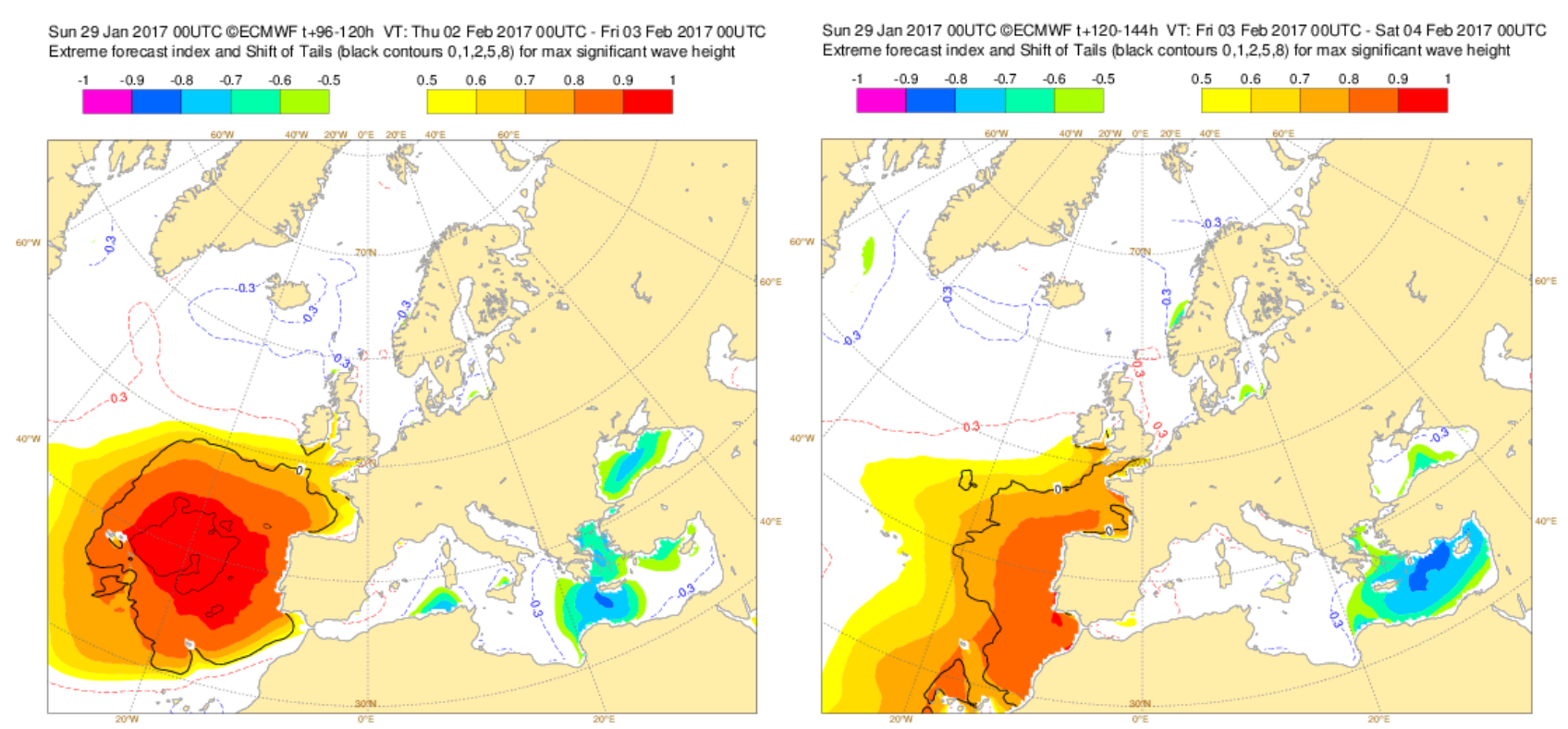

Figura 54.3: Extreme Forecast Index (EFI) previsto el día 29 de enero para los días 2 de febrero (izquierda) y 3 de febrero (derecha). ECMWF 2017.

Por otro lado, los mapas climatológicos de percentiles (sec. 27.7.1 en la página 419) 90 y 99 de altura de ola (Figura 54.4) muestran la rareza de que se alcancen en estas fechas los 8 metros necesarios para la emisión de un aviso rojo en nuestras costas.

Los mapas de promedio y dispersión (sección 27.5.1 en la página 412) de presión en superficie del día 29 a las 00 UTC (Fig. 54.5 en la página siguiente) comienzan a situar la primera baja L1 en torno a las 00 UTC del día 3 en las proximidades de Galicia. El campo medio mean sea level pressure -presión reducida al nivel medio del mar- (MSLP) del ECENS (izquierda) muestra un surco en la presión cerca de Galicia con valores de desviación estándar (derecha) superiores a $7 \mathrm{hPa}$ dando cuenta de la incertidumbre de su posición y profundidad. El modelo ECHRES (derecha, sec. 19.2 en la página 291) muestra ya una baja cerrada al noroeste de Galicia.
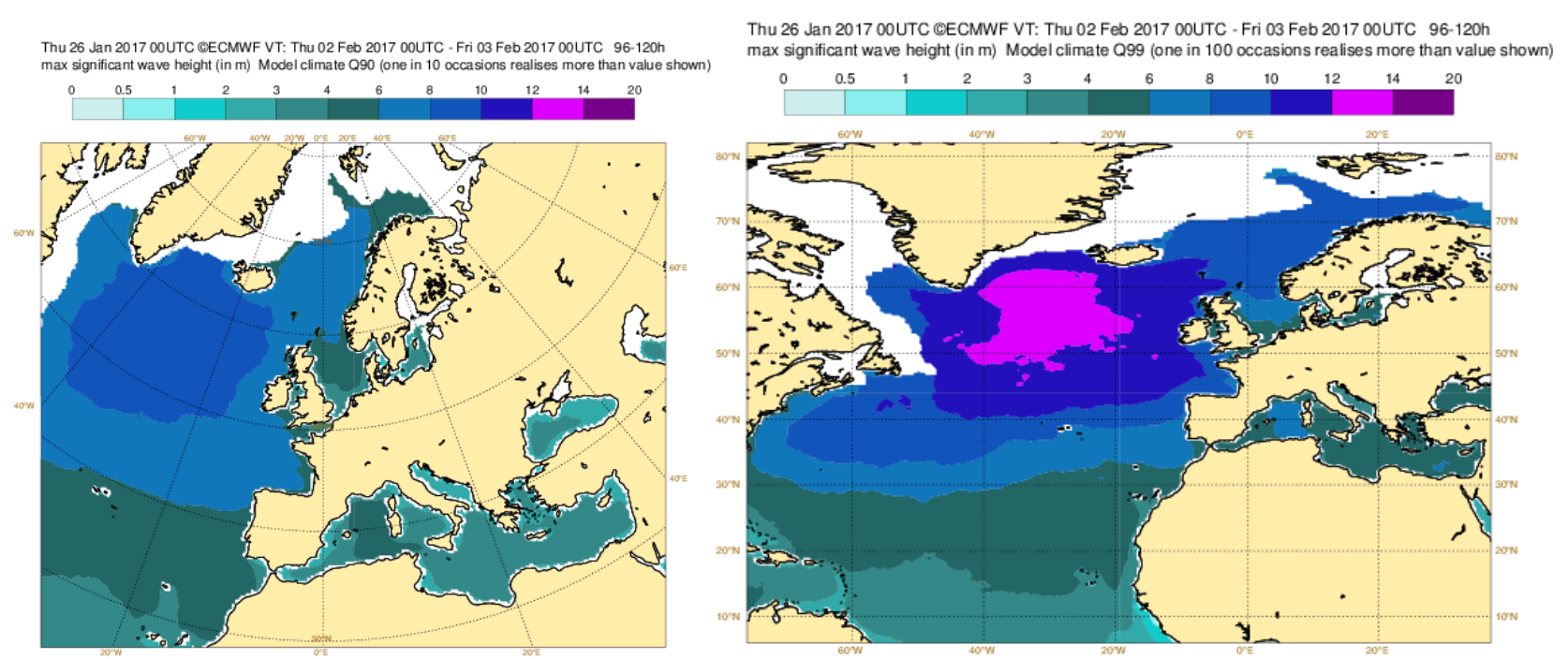

Figura 54.4: Percentiles 90 y 99 de la climatología de altura de ola correspondiente a estas fechas. ECMWF 2017. 

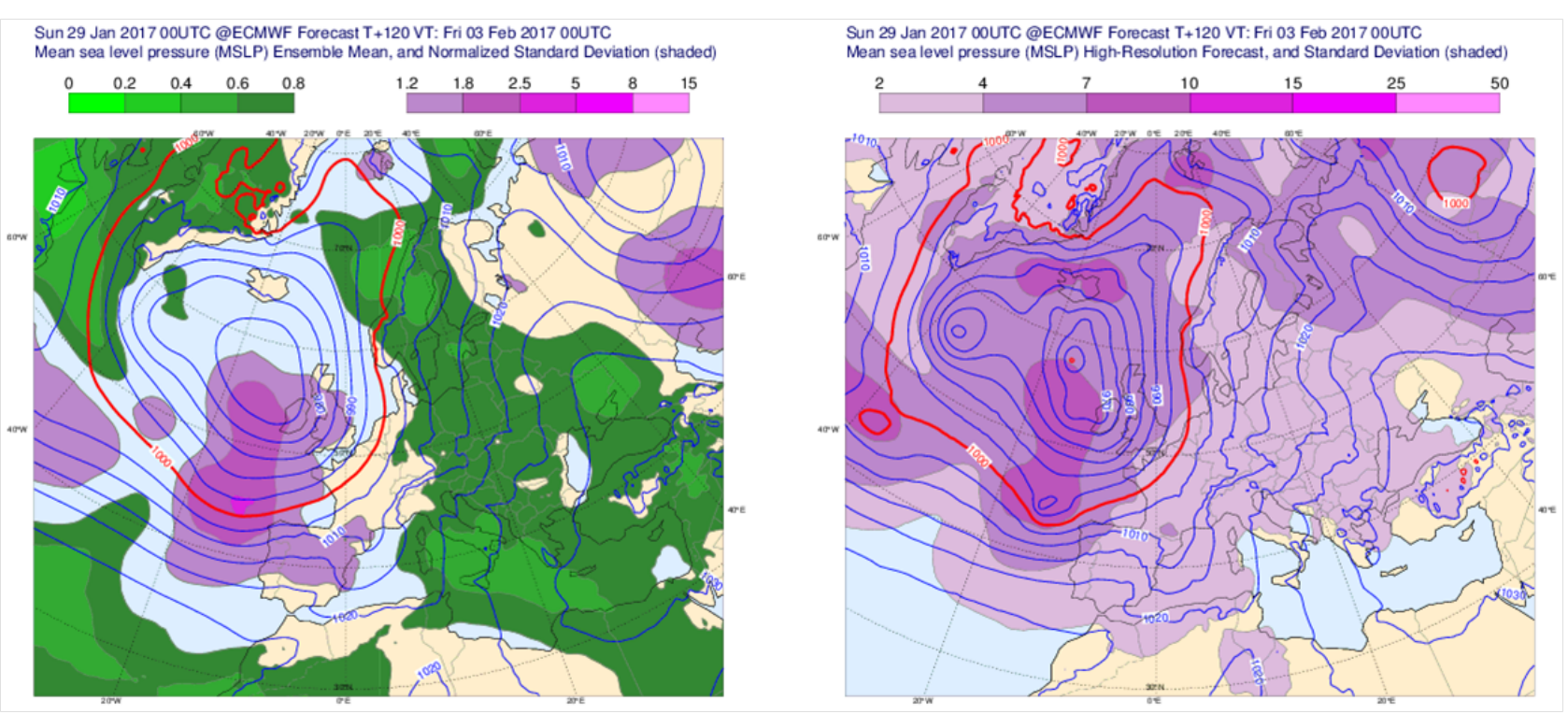

Figura 54.5: Mapas previstos el día 29 de enero para el 3 de febrero a las 00 UTC $(H+120)$ de la presión al nivel del mar: a la izquierda, media del ECENS (Ensemble Mean) y a la derecha, predicción del modelo de alta resolución ECHRES con la desviación estándar del ECENS sombreada. ECMWF 2017.

48 horas más tarde, el día 31 de enero, (Fig. 54.6) se reduce la indeterminación que el ECENS atribuye a L1 sugiriendo ya el promedio un mínimo cerrado de presión al noroeste de Galicia y previendo el ECHRES una mayor profundidad de la baja L1 aunque en una posición diferente a la prevista 48 horas antes.

A la vista de ello, el día 31 se emite aviso naranja por olas superiores a 7 metros para la tarde del día 2 en las aguas costeras de Galicia.

Respecto a la baja L2, las Figuras 54.7 y 54.8 en la página siguiente muestran los correspondientes mapas previstos por las pasadas del 29 y 31 de enero respectivamente para el día 4 de febrero a las 00 UTC. Es evidente la disminución de la desviación estándar en torno a L2 a medida que se reduce el alcance de la predicción.
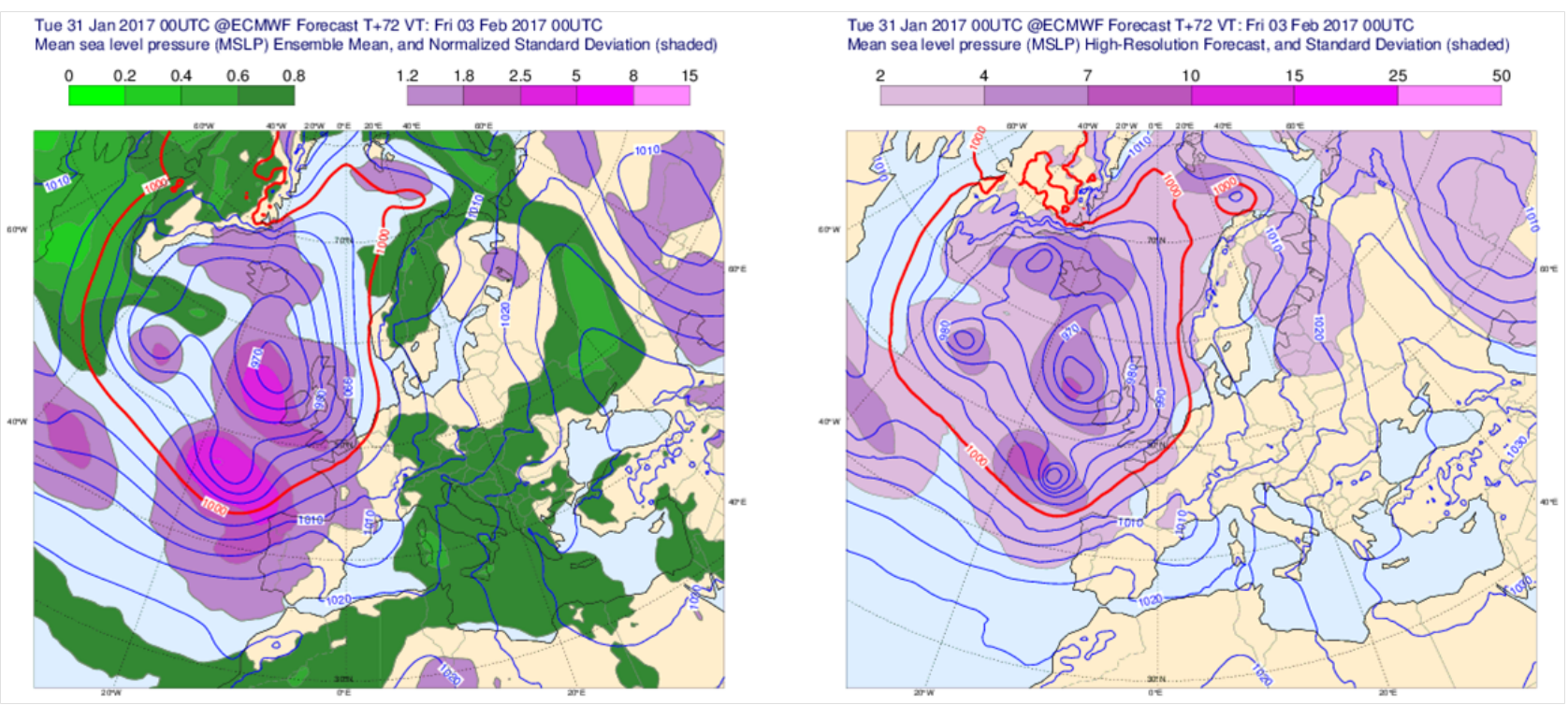

Figura 54.6: Similar a la Figura 54.5 pero con la previsión $(H+72)$ realizada el 31 de enero. ECMWF 2017. 

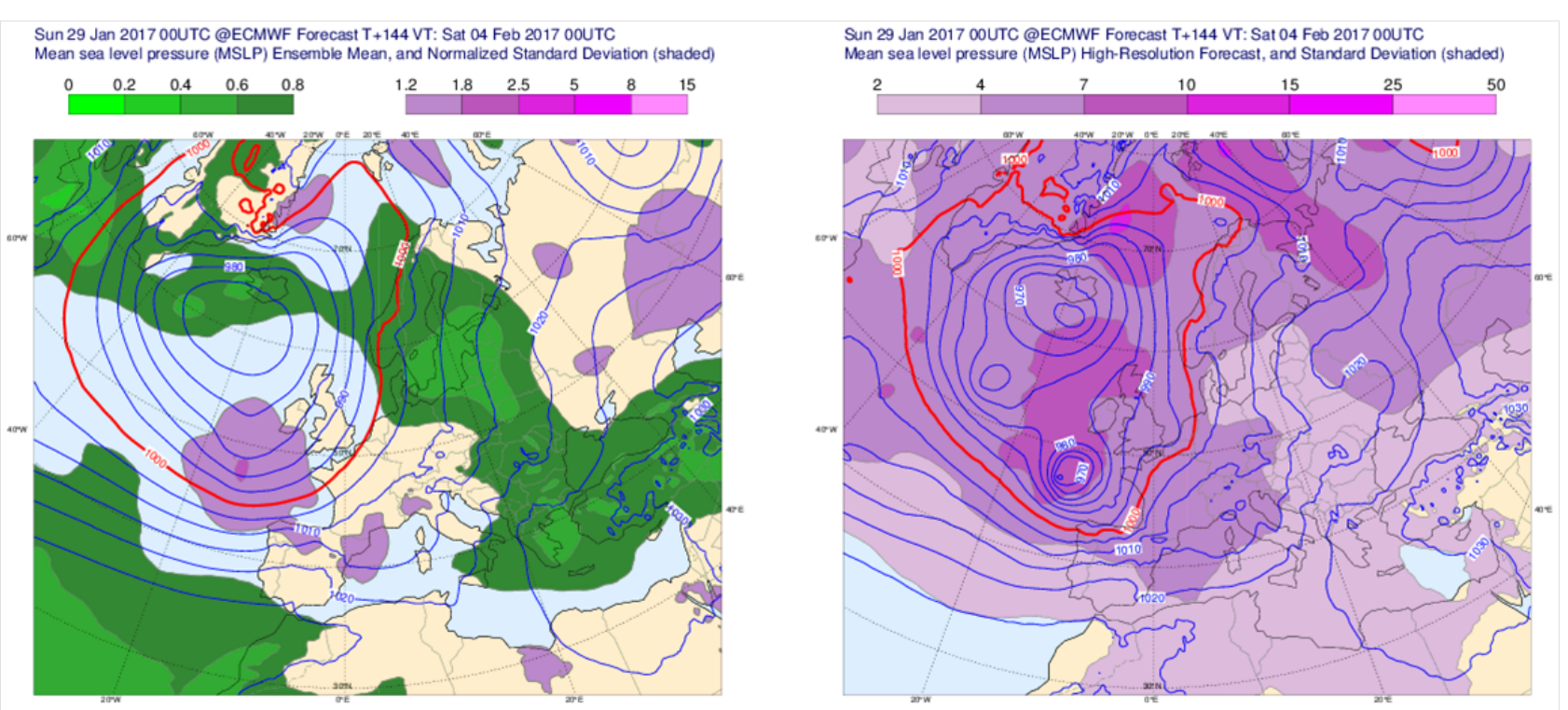

Figura 54.7: Similar a la Figura 54.5 pero con la previsión $(H+144)$ para el día 4 de febrero a las 00 UTC. ECMWF 2017.

A partir del día 1 los mapas de probabilidad de altura de mar de viento y de mar compuesta o combinada (Figura 54.9 en la página siguiente) muestran un gradiente de probabilidad más reducido, indicando una dispersión en los miembros del ECENS lo suficientemente baja como para utilizar el modelo ECHRES de alta resolución con un enfoque más determinista al tiempo que aporta más información a la predicción.
Esto se debe principalmente a que el predictor dispone de más campos y de sus valores con una mayor resolución espacial (9 km sobre 18 km en 2017). En consecuencia el ECHRES puede dar valores de algunas variables más extremos de los que aparecerían con una resolución más baja, e.g. mínimos de presión o máximos de viento.
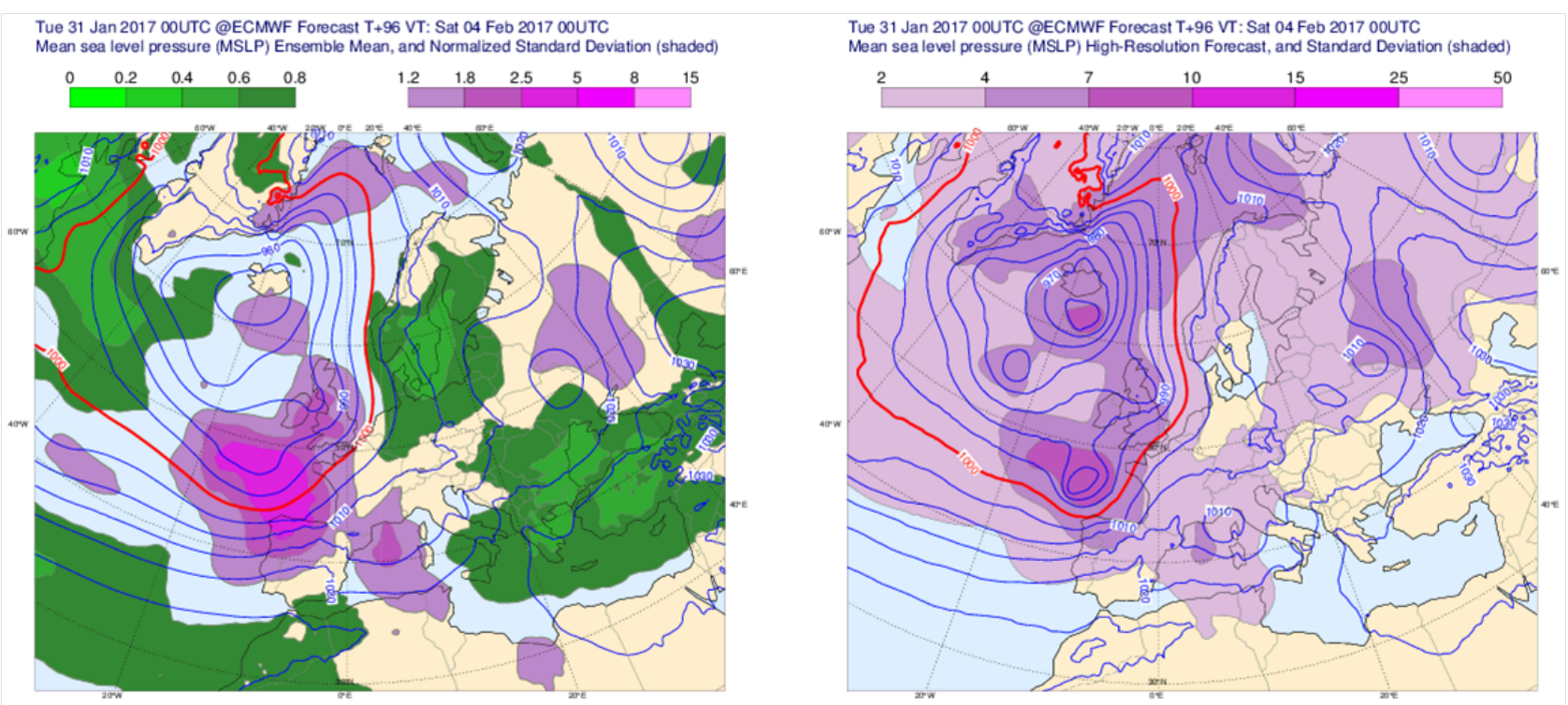

Figura 54.8: Similar a la Figura 54.6 pero con la previsión (H+96) para el día 4 de febrero a las 00 UTC. ECMWF 2017. 

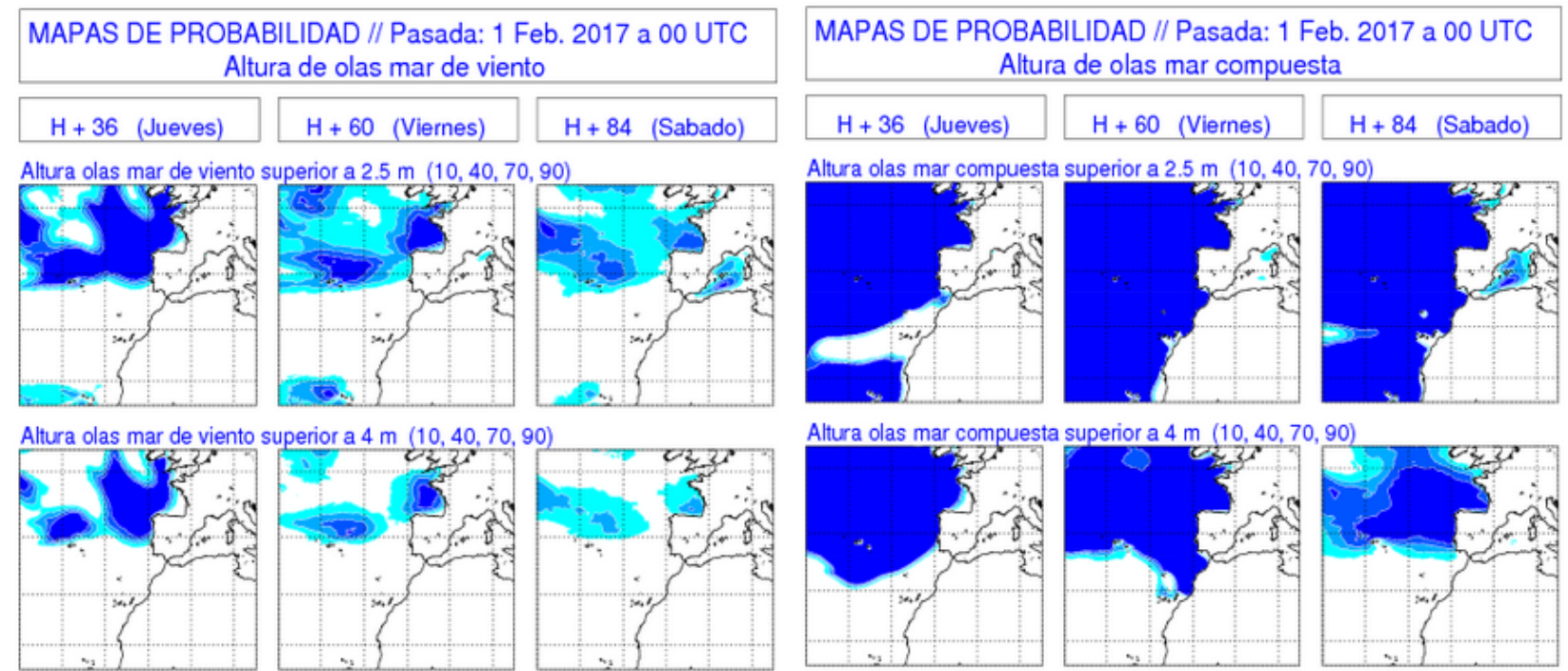

Altura olas mar de viento superior a $6 \mathrm{~m}(5,10,40,70)$

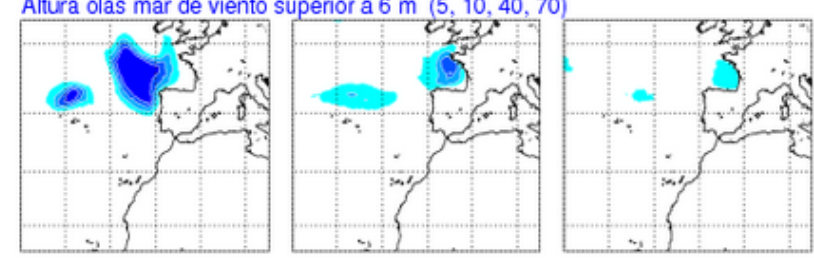

Altura olas mar de viento superior a $9 \mathrm{~m}(5,10,40,70)$
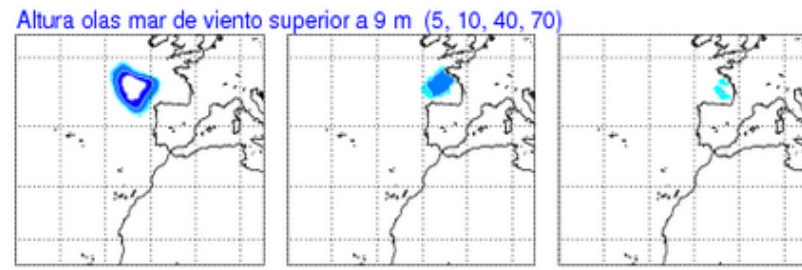

Altura olas mar compuesta superior a $4 \mathrm{~m}(10,40,70,90)$

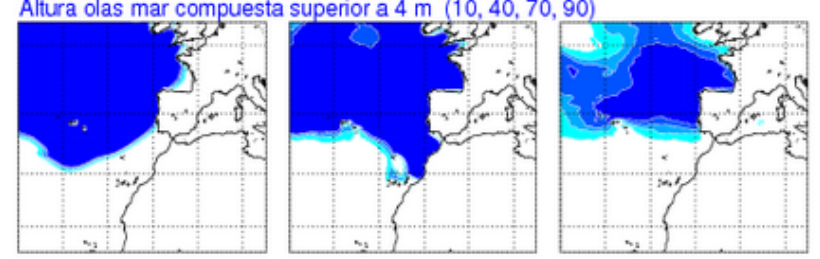

Altura olas mar compuesta superior a $6 \mathrm{~m}(5,10,40,70)$

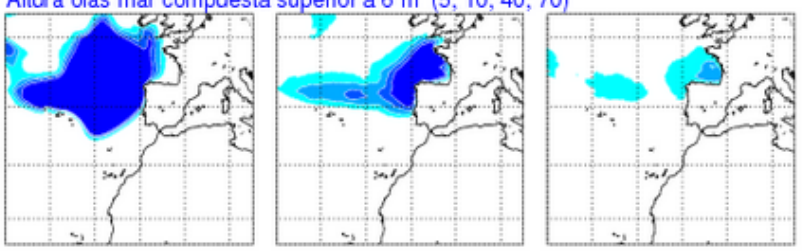

Altura olas mar compuesta superior a $9 \mathrm{~m}(5,10,40,70)$

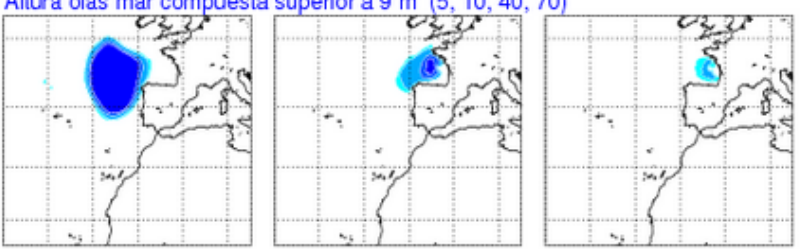

Figura 54.9: Mapas de probabilidad de la altura de mar de viento y de mar compuesta correspondientes a la pasada de 00 UTC del 1 de febrero para los días 2, 3 y 4. Para los umbrales 2.5 y $4 \mathrm{~m}$ los intervalos de probabilidad son blanco $=0-10 \%$, celeste $=10-40 \%$, azull $=40-70 \%$, azul2 $=70-90 \%$, azul3 $=90-100 \%$; para los umbrales de 6 y $9 \mathrm{~m}$ son blanco=0-5\%, celeste $=5-10 \%$, azull=10-40\%, azul2=40-70\%, azul3=70-100\%). AEMET 2017.

\subsection{Emisión de avisos}

Si tomamos como base el modelo ECHRES de alta resolución del ECMWF del día 1 de febrero de 2017 a las $00 \mathrm{UTC}$, podemos comprobar que el/la predictor/a ya tenía datos suficientes para la emisión de avisos de color rojo por oleaje ( $>8 \mathrm{~m}$ de mar combinada) en distintas zonas de la costa de Galicia. Otra variable que contribuye a la decisión en la emisión de avisos es la potencia del oleaje; valores de $700 \mathrm{Kw} / \mathrm{m}$ cercanos a la costa nos dan idea de la importante energía que acompañaba a este oleaje, algo que apoya la decisión de emitir avisos de nivel rojo. Un resumen de avisos emitidos se muestra en la Figura 54.10 en la página siguiente.

El comportamiento del modelo ECHRES en el corto plazo se puede examinar tomando como ejemplo el alcance $\mathrm{H}+42$ de dicho modelo y comparándolo con el análisis posterior para ese alcance, como se muestra en las Figuras 54.11, 54.12 y 54.13 en la página 823. De esa forma, se puede comprobar que su previsión se aleja poco de su propio análisis lo que, a su vez, avala la decisión tomada de emitir los avisos rojos.

Este episodio no coincidió con valores significativos de los coeficientes de marea. Cuando dichos valores son altos (mareas vivas) deben ser tenidos en cuenta para la determinación del nivel de aviso. 


\section{AVISOS EMITIDOS}

DIA 1 FEBRERO 2017

MAÑANA

\begin{tabular}{|ll|l|}
\hline W CORUNA & desde $15 \mathrm{~h}$ dia 2 hasta $23 \mathrm{~h}$ dia 2 & $8-9 \mathrm{~m}$ \\
SW CORUÑA & &
\end{tabular}

\begin{tabular}{|ll|l|}
\hline NW CORUÑA & desde $16 \mathrm{H}$ dia 2 hasta $23 \mathrm{~h}$ dia 2 & $8-9 \mathrm{~m}$ \\
\cline { 2 - 2 } &
\end{tabular}

NOCHE IGUAL

\section{DIA 2 FEBRERO 2017}

MAÑANA

\begin{tabular}{|c|c|c|}
\hline \multirow{2}{*}{\multicolumn{2}{|c|}{$\begin{array}{l}\text { W CORUNA desde } 15 \text { h dia } 2 \text { hasta } 23 \text { h dia } 3 \\
\text { NW CORUÑA }\end{array}$}} & $8-9 \mathrm{~m}$ ocas $10 \mathrm{~m}$ \\
\hline & & ocas F 9-10 \\
\hline
\end{tabular}

\begin{tabular}{|c|c|c|}
\hline \multirow{2}{*}{\multicolumn{2}{|c|}{$\begin{array}{l}\text { SW CORUÑA desde } 15 \mathrm{H} \text { dia } 2 \text { hasta } 11 \mathrm{~h} \text { dia } 3 \\
\text { PONTEVEDRA }\end{array}$}} & 8-9 m \\
\hline & & ocas F 9-10 \\
\hline
\end{tabular}

\begin{tabular}{|l|l|l|}
\hline LUGO & desde $4 \mathrm{~h}$ dia 3 hasta 8 h dia 3 & F 8 ocas F 9-10
\end{tabular}

NOCHE IGUAL

\section{DIA 3 FEBRERO 2017}

MAÑANA

\begin{tabular}{|lr|l|}
\hline W CORUÑA & desde $10 \mathrm{~h}$ dia 3 hasta $13 \mathrm{~h}$ dia 3 & $8-9 \mathrm{~m}$ \\
\cline { 2 - 3 } & & \\
NW CORUÑA & &
\end{tabular}

\begin{tabular}{|ll|l|}
\hline $\begin{array}{l}\text { SW CORUNA } \\
\text { PONTEVEDRA }\end{array}$ & desde $10 \mathrm{~h}$ dia 3 hasta $11 \mathrm{~h}$ dia 3 & $8-9 \mathrm{~m}$ \\
\cline { 2 - 3 } & &
\end{tabular}

\begin{tabular}{|ll|l|}
\hline LUGO & desde 18h dia 3 hasta Oh dia 4 & F 8-9 \\
W CORUÑA & & $6-8 \mathrm{~m}$ \\
\hline NW CORUÑA & &
\end{tabular}

NOCHE

\begin{tabular}{ll}
\hline LUGO & desde $22 \mathrm{~h}$ dia 3 hasta $0 \mathrm{~h}$ dia 4 \\
W CORUÑA & \\
NW CORUÑA & \\
\hline
\end{tabular}

F 8-9
$8-9$ al final CORUÑA

Figura 54.10: Resumen de los avisos rojos emitidos desde el día 1 de febrero hasta el día 3 de febrero. 

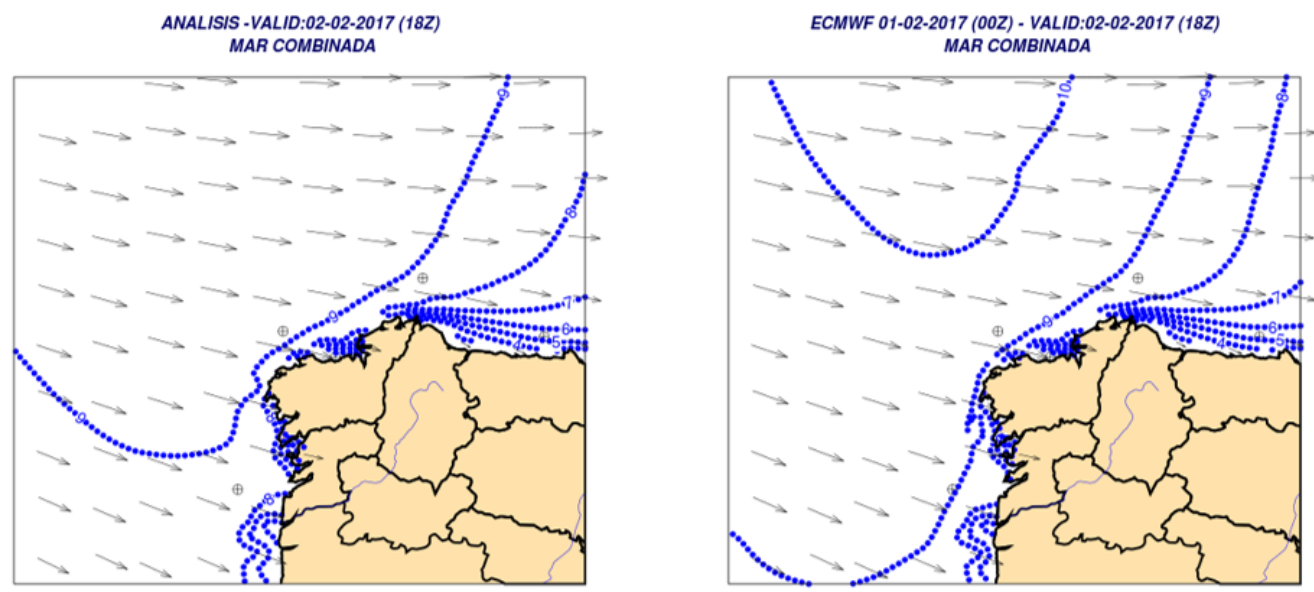

Figura 54.11: Análisis del día 2 a las 18 UTC y predicción $(H+42)$ del modelo ECHRES del día 1 para el día 2 a las 18 UTC. Altura (isolíneas contorneadas cada metro) y dirección (flechas) de mar combinada.
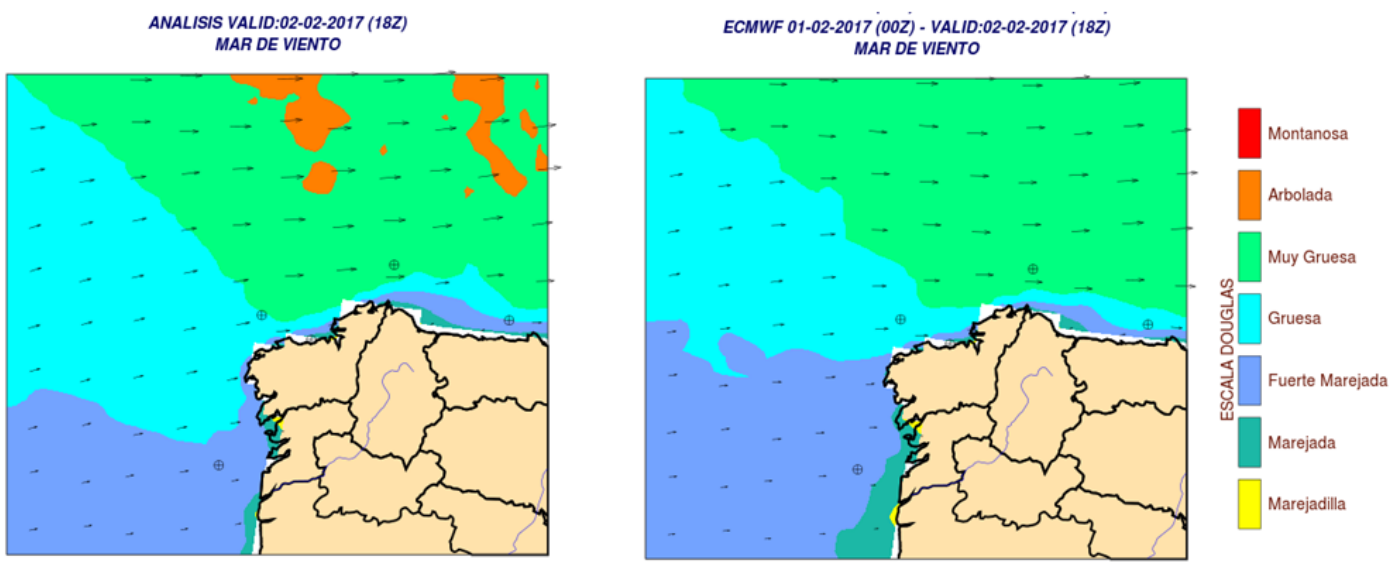

Figura 54.12: Análisis y predicción como en la Figura 54.11. Mar de viento.
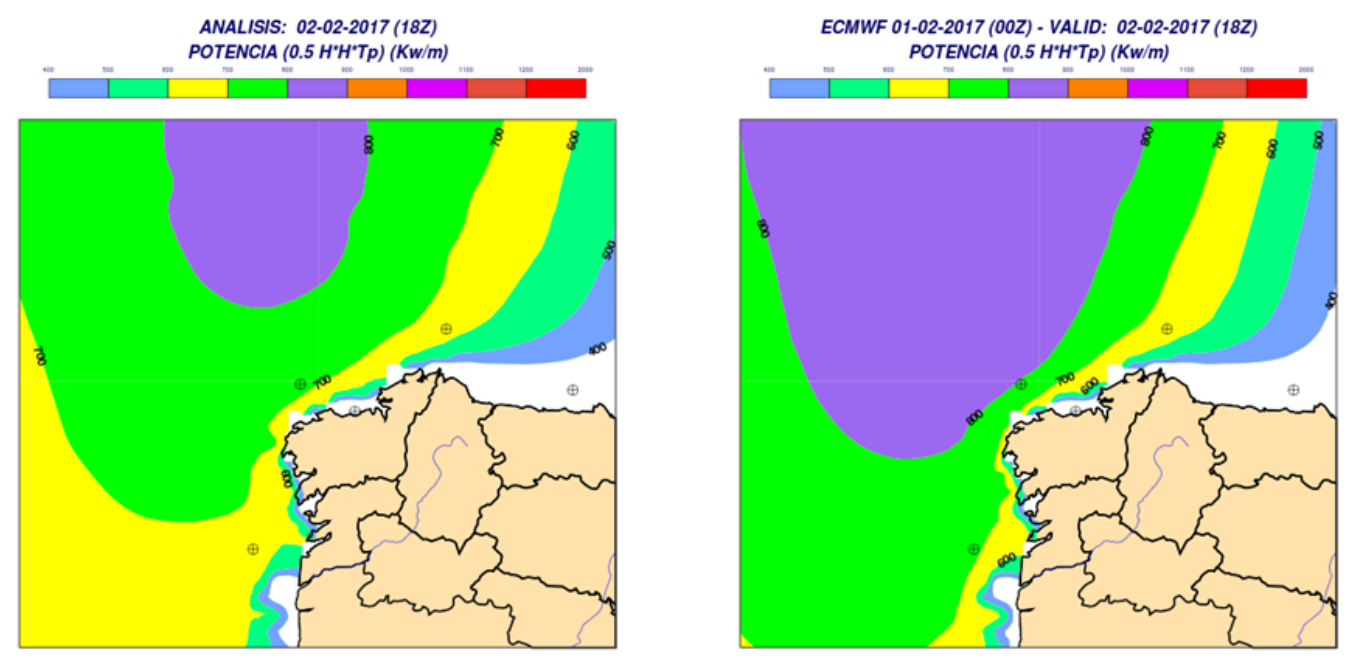

Figura 54.13: Análisis y predicción como en la Figura 54.11. Potencia. 

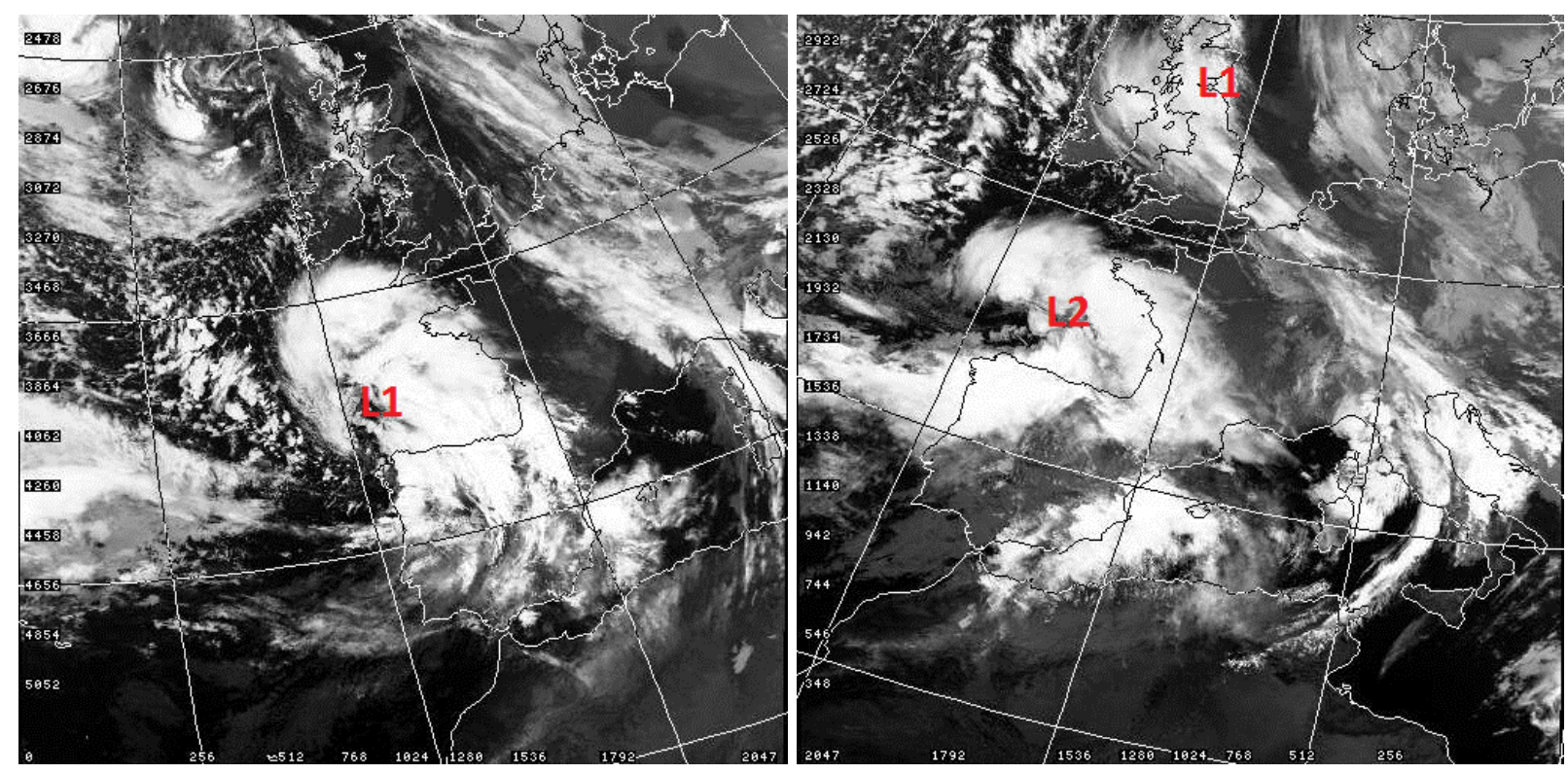

Figura 54.14: Imágenes infrarrojas (canal 4 del AVHRR) de las bajas L1 y L2 captadas por los satélites de órbita polar NOAA19 a las 04.04 UTC (izquierda) y MetOp-B a las 20.58 UTC (derecha) el día 3 de febrero. Dundee Satellite Receiving Station, Dundee University, UK.

\subsection{Evolución observada de la si- tuación}

En la Figura 54.14 se muestran dos imágenes infrarrojas captadas, con unas 17 horas de diferencia, por satélites de órbita polar el día 3 de febrero con la posición aproximada de las bajas L1 y L2 y que permiten apreciar la rapidez de sus desplazamientos.

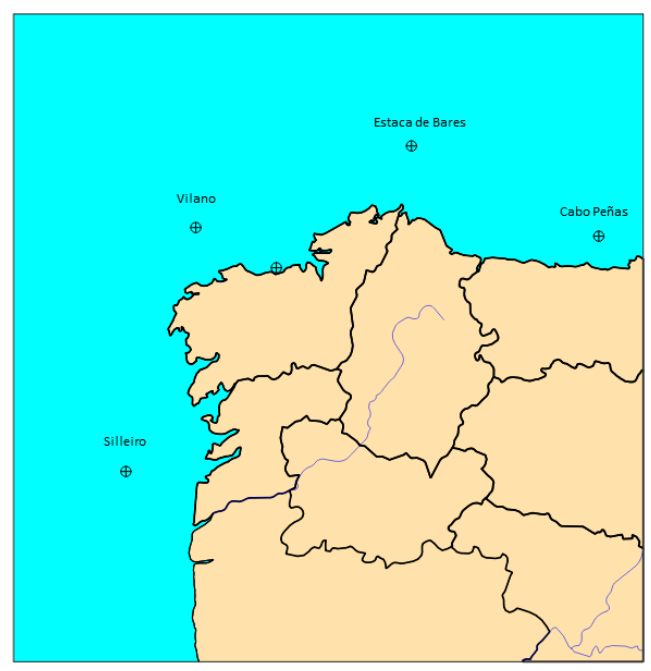

Figura 54.15: Situación de las boyas utilizadas. Puertos del Estado, Ministerio de Fomento.
Utilizando los datos extraídos de las boyas disponibles de Puertos del Estado (Ministerio de Fomento) podemos evaluar en parte la validez de los avisos emitidos y verificar las predicciones de los modelos. La situación de las boyas utilizadas se muestra en la Figura 54.15.

Potencia del oleaje.

$$
\phi \approx \frac{1}{2} T_{p} H_{s}^{2} \quad \text { calculada en } \mathrm{kW} / \mathrm{m}
$$

- Periodo de Pico $T_{p}$ : periodo del grupo de ondas con más energía

- Altura significativa $H_{s}$ : altura media del tercio de las olas más altas en el espectro del oleaje

- Watio / $\mathrm{m}=$ Julio / $\mathrm{m}$ seg $\Rightarrow$ energía por unidad de tiempo y longitud

En las figuras 54.16 y 54.17 en la página siguiente se muestran la altura de oleaje y su potencia, registradas por las cuatro boyas y los valores correspondientes al análisis del modelo ECHRES (ECMWF en la figura) en esos puntos así como sus diferencias. También aparece destacada la altura correspondiente a los 8 metros de mar combinada correspondiente al umbral de aviso rojo. 


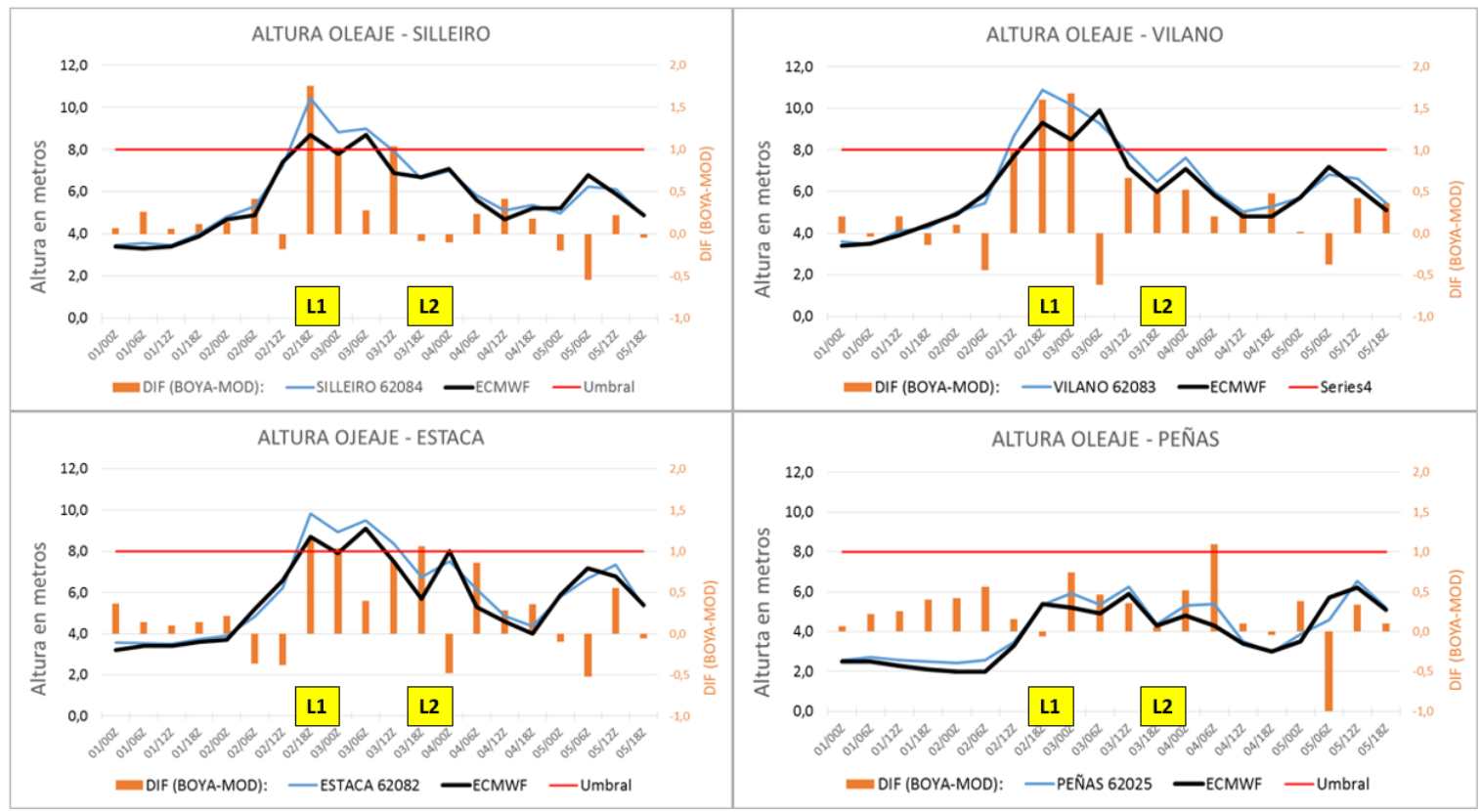

Figura 54.16: Altura de mar combinada. Análisis del modelo frente a boya y diferencia.

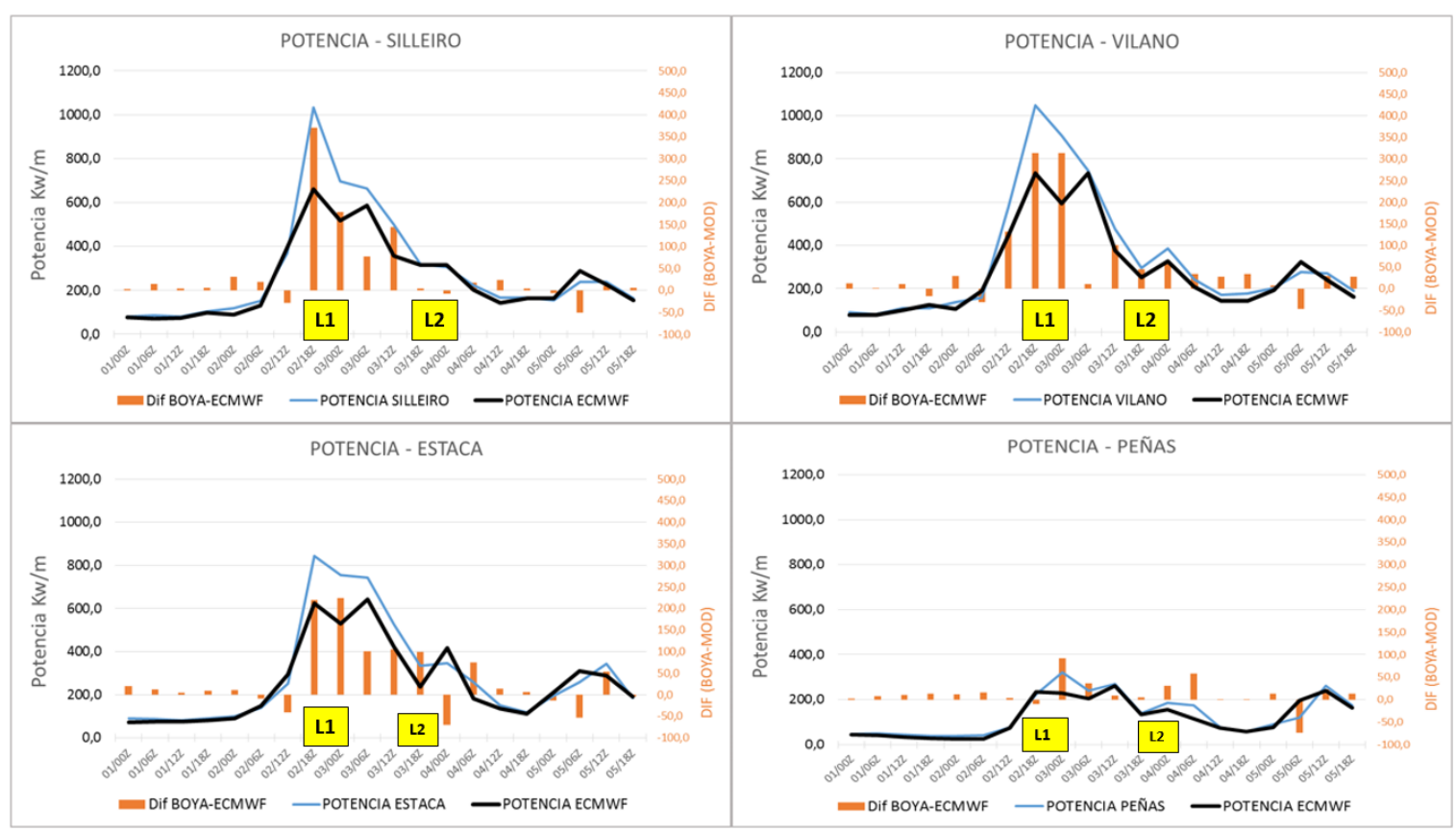

Figura 54.17: Potencia del oleaje (ver caja de texto). Análisis del modelo frente a boya y diferencia.

Con el paso de la baja L1 se observan registros que superaron los 10 metros. El paso de L2 produjo medidas cercanas a los 8 metros. De los datos mostrados se deduce que en el primer episodio el modelo subestima claramente los valores de altura y periodo, y por lo tanto de la potencia (diferencias superiores a $300 \mathrm{Kw} / \mathrm{m}$ en Silleiro y Vilano). No así en el segun- do (L2) en que los datos son similares. Respecto a la validez de los avisos, con la limitación que supone el pequeño número de registros disponibles, se puede concluir que se alcanzaron los umbrales previstos para el nivel rojo en las zonas correspondientes y en los dos episodios (L1 y L2), aunque más claramente en el primero. 


\subsection{Referencias}

[1] Persson, Anders. "User guide to ECMWF forecast products". En: Ecmwf March (2011), página 127 (citado en página 816). 
